\title{
TEM Study of Microstructure Evolution in Novel Environmentally Friendly Si alloyed Lead-free Brasses
}

\author{
Sylvia Zormalia ${ }^{1}$, Petros Tsakiridis ${ }^{1}$ and George Fourlaris ${ }^{1}$ \\ 1. Lab. of Physical Metallurgy, School of Mining and Metallurgical Engineering, National Technical \\ University of Athens, Heroon Polytechniou 9, Athens, Greece.
}

The progressively stricter European and American regulations (California Health and Safety Code (AV1953), Vermont Act 193, Directive 2002/95 / EC (RoHS), Drinking water directive 98/38 / EC, German DIN 50930-6, Italian DM Salute 6 aprile 2004 n.174 and French Arreté 29 Mai 1997) [1], in conjunction with lead leaching studies on drinking water, have stimulated the development of unleaded brass maximum permitting levels of $\mathrm{Pb}$ up to $0.2 \mathrm{wt} \%$. Many studies have been contacted on lead-free brasses with several different additions, but the effect of Si content on the microstructure evolution and control, via TEM characterisation techniques has not been properly addressed to-date. Leaded brasses have 3-7\% wt $\mathrm{Pb}$ additions, primarily for enhanced machinability characteristics, as well as improved aqueous corrosion resistance, while the lead free alloy studied ,has a composition of $75.85 \%$ wt $\mathrm{Cu}, 3.4 \%$ wt $\mathrm{Si}, 0.02 \% \mathrm{wtFe}$ and $20.75 \%$ wtZn.

Based on this alloy composition, this eco-brass is placed close to the peritectic point, as defined by Fig.1, hence it is predicted to have in its microstructure the following three phases $\alpha(\mathrm{fcc}), \gamma(\mathrm{bcc})$ and $\kappa(\mathrm{hcp})$, while at approximately $550^{\circ} \mathrm{C}$ the following reaction is expected to take place, $\alpha+\kappa \Rightarrow \gamma$.

In Fig. 2 the presented SEM micrographs, give an outline of the microstructure features of these three phases, appropriately marked and identified via both XRD trace analysis, as well as EDS spotmicroanalyses. $\alpha$-phase has an fcc crystal structure (fcc, Fm3m), $\kappa$-phase an hcp (hcp, P63/mmc) and $\gamma$-phase a bcc crystal structure (bcc, I43m). In addition, to these principal phases the presence of a minor intermetallic, $\mathrm{Fe}_{\mathrm{x}} \mathrm{Si}_{\mathrm{y}}$, precipitate was detected both within $\gamma$ and $\kappa$ phases (fig.2). From the detailed EDS microanalyses performed both on the SEM and on the TEM, it has been confirmed that $\alpha$ phase has a composition of $1.78 \pm 0.28 \mathrm{Si}, \kappa$ phase, $3.55 \pm 0.29 \mathrm{Si}$ and finally $\gamma$ phase is significantly enriched in $\mathrm{Si}$, having an average composition of $5.94 \pm 0.38 \mathrm{Si}$. $\alpha$-phase is also prone to formation of Widmanstatten needles upon cold deformation.

The fine details of the TEM microstructures for $\kappa$ and $\alpha$ phases microstructures, are given in Fig.3, while for $g$ phase in Fig. 4. The heavily dislocated substructure is evident in both micrographs, as well as the presence of Widmanstatten needles with $\alpha$ phase and deformation twins within $\kappa$-phase.

The present study has highlighted the important modification on microstructure features present in $\mathrm{Si}$ alloyed eco-brasses, a result of $\mathrm{Pb}$ replacement by $\mathrm{Si}$. The refined microstructure of $\mathrm{g}$ phase, with its enhanced Si content, is considered to be crucial for attaining suitable machinability characteristics in eco-brasses. It is envisaged that with revised thermomechanical processing routes applied, fine tuning of the excellent machinability characteristics and aqueous water corrosion resistance will be attained.

\section{References:}

[1] G. Mueller.: Proceedings of the IWCC General Assembly, (2009), p.7.

[2] J.Miettinen, Computer Coupling of Phase Diagrams and Thermochemistry, Vol.31(2007), p.422. 

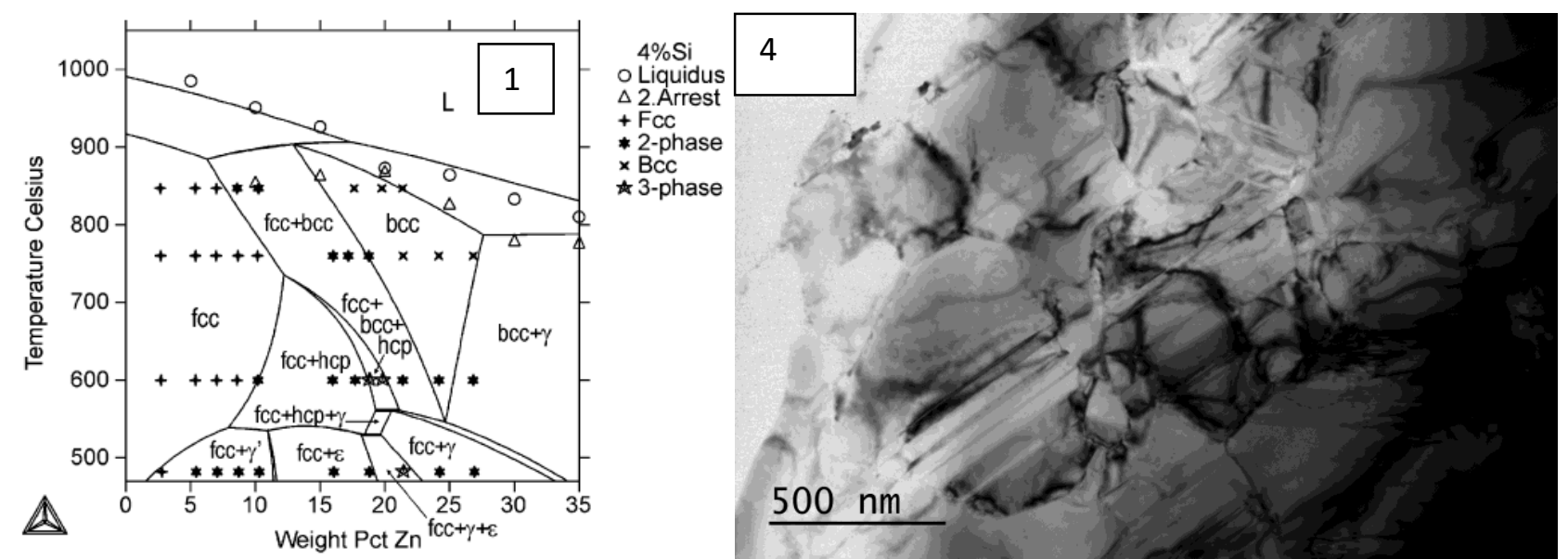

Figure 1. $\mathrm{Cu}-\mathrm{Si}-\mathrm{Zn}$ phase diagram for a $4 \% \mathrm{wt} \mathrm{Si}$ addition [2].
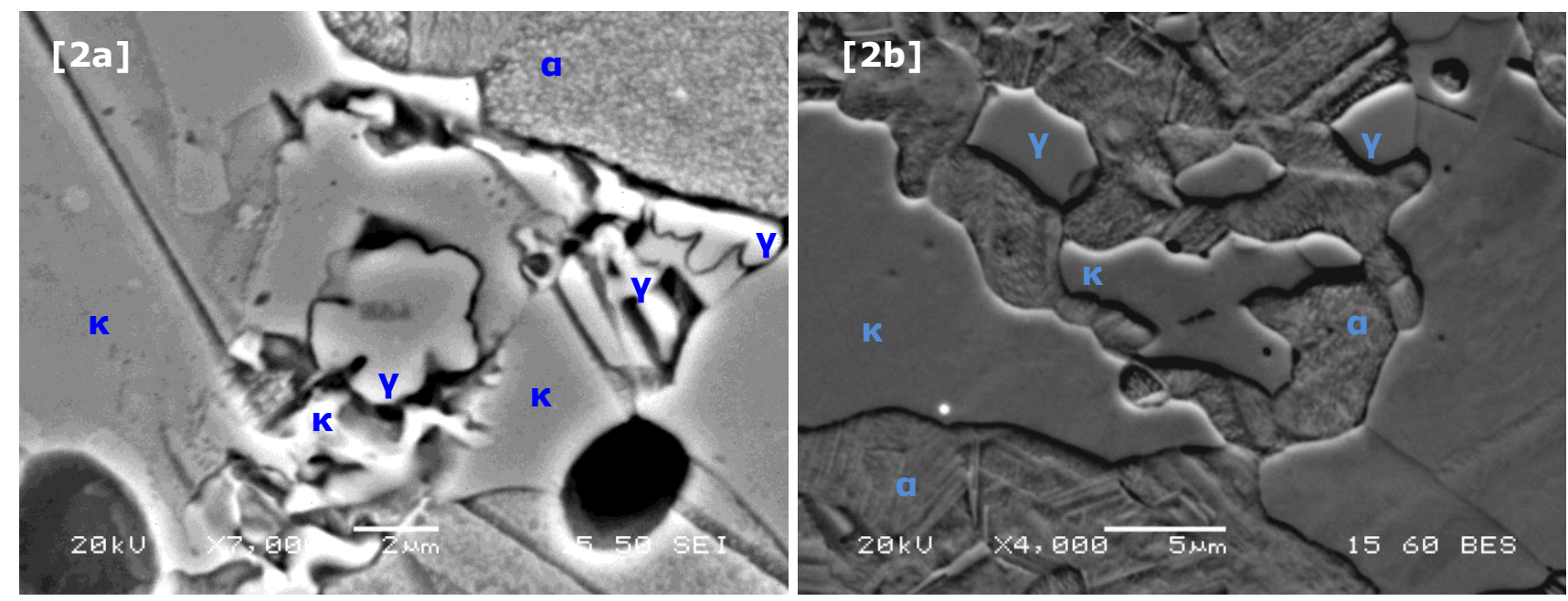

Figure 2. Secondary (2a) and Backscattered (2b) micrographs, outlining the morphological features of $\alpha, \kappa$ and $\gamma$ phases, as well as the $\mathrm{Fe}_{x} \mathrm{Si}_{\mathrm{y}}$ intermetallic phase, within $\gamma$-phase(2a) and within $\kappa$ phase (2b).

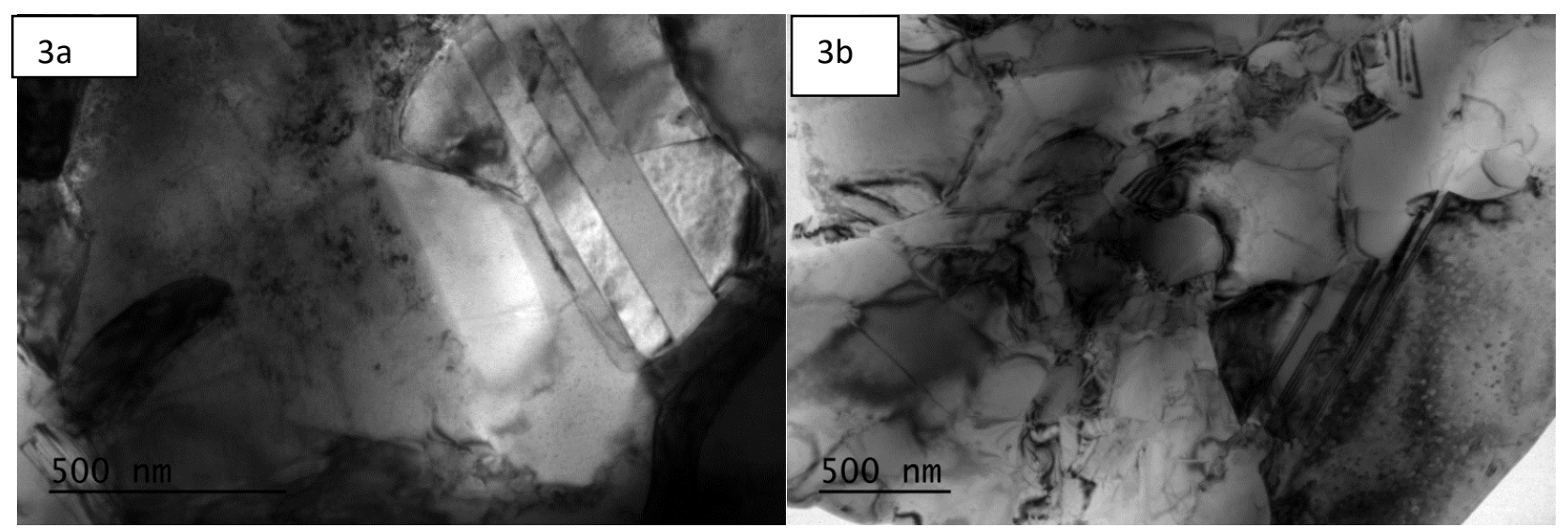

Figures 3 and 4. TEM bright field micrographs of $\kappa$-phase (3a), $\alpha$-phase (3b) and $\gamma$ phase (4), within a heavily dislocated substructure in as received eco-brass. 